\title{
LETTER
}

\section{INTERSEPT study: we still need more clarity}

\author{
Flavia R Machado*1, Milton Caldeira-Filho², Rubens Costa-Filho ${ }^{3}$, Ciro Leite Mendes ${ }^{4}$, Suzana Margareth Lobo ${ }^{5}$, \\ Eduardo Eiras Moreira da Rocha ${ }^{6}$, Jose Mario Telles ${ }^{7}$ and Glauco Westphal ${ }^{8}$ \\ See related research by Pontes-Arruda et al., http://ccforum.com/content/15/3/R144, and related letter by Machado, \\ http://ccforum.com/content/15/5/449, which includes a response by Pontes-Arruda
}

In recent issues of Critical Care, we read with concern the article by Pontes-Arruda and colleagues [1] and the first author's reply to the letter from Machado (the latter two of which appear in [2]). The article and subsequent letters address eicosapentaenoic acid/gamma-linolenic acid (EPA/GLA) use in sepsis patients in the INTERSEPT (Investigating Nutritional Therapy with EPA, GLA and Antioxidants Role in Sepsis Treatment) study.

We served as the principal investigators of this trial and come from sites that did not successfully include any patients or that included only a small number of patients. From this vantage point, we believe that Pontes-Arruda's reply to Machado's comments [2] did not clarify several important points.

As stated in the article [1], only five of the 12 sites successfully enrolled patients. However, the first author's site was responsible for the inclusion of about 100 of the 106 patients. We believe that this imbalance is relevant and that readers of Critical Care need to be aware of it. We disagree with Pontes-Arruda's response [2] that all relevant limitations were already mentioned in the Discussion [1]. We found it difficult to understand his affirmation that the results were unaffected by the unbalanced distribution pattern of the patients, as any statistical analysis of the few patients from the other four sites would obviously be underpowered. We also think he should clearly state the strategies that were used at his site to successfully enroll patients given that the 11 other sites, most of which are very skilled at performing intervention studies, failed to enroll similar numbers of patients.

The author's explanation [2] of the Sequential Organ Failure Assessment (SOFA) findings is also not clear. We agree that it is perfectly possible for some patients to have a high SOFA score that may be insufficient to fulfill the inclusion criteria. However, the median and interquartile values shown in Table 3 [1] indicate that $75 \%$ of all patients had a SOFA score of more than 4 . This would be a very unusual finding in sepsis patients without significant organ dysfunction. Moreover, the interquartile interval in Table 3 indicates that at least $75 \%$ of the patients had platelet levels of more than $144 \times 10^{9}$ cells per liter, a bilirubin level of less than $1.5 \mathrm{mg} / \mathrm{dL}$, and a creatinine level of less than $1.6 \mathrm{mg} / \mathrm{dL}$; as stated in the text [1], no patients had an arterial partial pressure of oxygen/ fraction of inspired oxygen $\left(\mathrm{PaO}_{2} / \mathrm{FiO}_{2}\right)$ ratio of less than 300. The high median and interquartile values for the SOFA scores would be possible only in the presence of severe neurological or hemodynamic dysfunction in the majority of the patients; this point, therefore, requires further explanation. Moreover, at least $50 \%$ of the patients had lactate levels of higher than $3.7 \mathrm{mmol} / \mathrm{L}$, and this suggests that many patients already had signs of hypoperfusion (that is, severe sepsis) at inclusion. We believe that this paper needs more clarity as all of the above aspects are relevant for readers of Critical Care.

\section{Author's response}

Alessandro Pontes-Arruda

Like any prospective randomized controlled trial, the INTERSEPT study has several limitations. As clearly

\footnotetext{
*Correspondence: fmachado.dcir@epm.br

${ }^{1}$ Hospital Sao Paulo, Anesthesiology and Critical Care Department, Universidade

Federal de Sao Paulo, R. Napoleao Barros 7155 a andar, Sao Paulo - SP, Brazil,

04024900

Full list of author information is available at the end of the article
}

mentioned in the paper [1], only five centers included patients. The primary center contributed $86 \%$ of them and such information was always available to all investigators on the trial website. The primary reason why some institutions included patients while some did not is simple and was shared with all other investigators during the trial: the adoption of a more proactive approach. Centers that manage to include patients searched for them in the emergency and general wards. If a patient 
was found and if a bed was available, they were transferred to be treated in the intensive care unit. This demands an extraordinary amount of time and effort, and many centers decided not to follow this strategy. But there are other reasons for the lack of inclusion in other centers: It was impossible to blind the diet in two of the institutions, because their nutrition was prepared by independent companies located outside the hospital. More importantly, some institutions were clearly not interested in participating in the trial; we have recorded that five centers did not use their secret log-in/password a single time, not even to receive the electronic Clinical Research Forum mandatory online training. We want to highlight that all necessary care was taken to ensure the highest standards of quality and strict protocol adherence for the included patients. After its conclusion, the study was submitted to an extensive audit, and all study records, databases, institutional review board approvals, diet controls, written informed consents, and original medical records of the primary center were checked by independent auditors without any interference of the investigators, and only after this quality-control audit was the study submitted for publication. In the text of Machado, there is an assumption that the the high median and interquartile values for the SOFA score would be possible only in the presence of severe neurological and hemodynamic dysfunction in the majority of the patients' and this assumption is incorrect. All patients, indeed, did have $\mathrm{PaO}_{2} / \mathrm{FiO}_{2}$ ratio of above 300, but many had $\mathrm{PaO}_{2} / \mathrm{FiO}_{2}$ ratio of between 400 and 300, representing 1 SOFA point. Similarly, a bilirubin level of 1.3 to $1.4 \mathrm{mg} / \mathrm{dL}$ and a platelet count of 144 to $149 \times 10^{9}$ cells per liter do represent 1 SOFA point. In regard to lactate levels of included patients, please see Table 2 [1] and observe that the levels are still below the limit considered for metabolic failure. Finally, many included patients were older patients suffering from stroke and concomitant pneumonia, and this obviously means that they have some SOFA points in their neurologic evaluation. This study, like many others, does have several limitations, including the fact that care should be taken to extrapolate the findings to the overall population of patients with early sepsis. However, we believe that the true value of the INTERSEPT study is to serve as guide for future trials, including trials of a larger population of patients to validate the results of the present study.

\section{Abbreviations}

EPA, eicosapentaenoic acid; GLA, gamma-linolenic acid; INTERSEPT, Investigating Nutritional Therapy with eicosapentaenoic acid, gammalinolenic acid and Antioxidants Role in Sepsis Treatment; $\mathrm{PaO}_{2} / \mathrm{FiO}_{2}$, arterial partial pressure of oxygen/fraction of inspired oxygen; SOFA, Sequential Organ Failure Assessment.

Competing interests

The authors declare that they have no competing interests.

\section{Author details}

'Hospital Sao Paulo, Anesthesiology and Critical Care Department, Universidade Federal de Sao Paulo, R. Napoleao Barros 715 a andar, Sao Paulo - SP, Brazil, 04024900. ${ }^{2}$ Hospital Dona Helena, R.Blumenau 123, Joinville - SC, Brazil, 89204205. ${ }^{3}$ Hospital Procardiaco, R. General Polidoro 192, Rio de Janeiro - RJ, Brazil, 22280000. ${ }^{4}$ Hospital Universitario, Universidade Federal da Paraiba -Campus I, Cidade Universitária - João Pessoa - PB, Brazil, 58000000. ${ }^{5 H}$ Hospital de Base - Intensive Care Division - Department of Internal Medicine, Faculdade de Medicina de São José do Rio Preto. Av. Faria Lima 5544, São Jose do Rio Preto - SP, Brazil, 15090000. ${ }^{6}$ Hospital Copa D'Or, R. Figueiredo de Magalhães, 875, Rio de Janeiro - RJ, 22031011. Formerly of Clinica Sao Vicente. ${ }^{7 H o s p i t a l}$ Santo Amaro. Ladeira do Campo Santo S/N, Salvador - BA, Brazil, 40210320. Formerly both of Hospital Portugues and Hospital Salvador, Salvador - BA, Brazil. ${ }^{8}$ Centro Hospitalar UNIMED Rua Orestes Guimaraes 905, Joinville - SC, Brazil, 89204060

Published: 13 March 2012

\section{References}

1. Pontes-Arruda A, Martins LF, de Lima SM, Isola AM, Toledo D, Rezende E, Maia M, Magnan GB: Enteral nutrition with eicosapentaenoic acid, gammalinolenic acid and antioxidants in the early treatment of sepsis: results from a multicenter, prospective, randomized, double-blinded, controlled study: the INTERSEPT study. Crit Care 2011, 15:R144.

2. Machado FR: Fish oil and sepsis: we still need more trials. Crit Care 2011, 15:449.

doi:10.1186/cc11192

Cite this article as: Machado FR, et al:. INTERSEPT study: we still need more clarity. Critical Care 2012, 16:416. 